Recepción: 05 / 06 / 2018

Aceptación: 25 / 07 / 2018

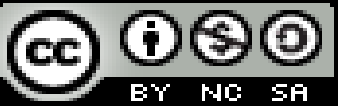

Ciencias de la salud

Publicación: 01 / 09 / 2018

\title{
La estética en la odontología restauradora
}

\section{The aesthetics in restorative dentistry}

A estética na odontologia restorativa

Juan M. Sierra-Zambrano ${ }^{\mathrm{I}}$ juansierraz@hotmail.com

Miguel Carrasco-Sierra II miguelcarrasco@hotmail.com

Victor A. Avendaño Robles III victoraravedaño@hotmail.com

Correspondencia: juansierraz@hotmail.com

IEspecialista en Patología y Cirugía Bucal, Odontólogo, Docente de la Universidad Laica Eloy Alfaro de Manabí, Manta, Ecuador.

\footnotetext{
II Especialista de Primer Grado en Prótesis Estomatológica, Master en Atención de Urgencias en Estomatología, Doctor en Estamologia, Docente de la Universidad Laica Eloy Alfaro de Manabí, Manta, Ecuador.
}

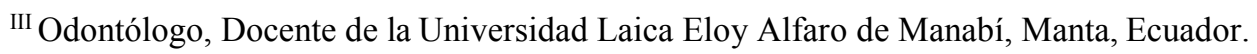




\title{
Resumen
}

La sonrisa es una de las expresiones faciales más importantes que diferencia al ser humano del resto de los animales. La utiliza como parte del lenguaje, expresando alegría, felicidad o placer. La población, solicita con frecuencia restauraciones compatibles con los estándares de la estética dental. Este trabajo involucra aspecto relacionados con la estética en la odontología restauradora.

Palabras claves: sonrisa; odontología restauradora: material restaurador.

\begin{abstract}
The smile is one of the most important facial expressions that differentiates the human being from the rest of the animals. He uses it as part of language, expressing joy, happiness or pleasure. The population frequently requests restorations compatible with the standards of dental aesthetics. This work involves aspects related to aesthetics in restorative dentistry.
\end{abstract}

Keywords: smile; restorative dentistry: restorative materials.

\section{Resumo}

O sorriso é uma das expressões faciais mais importantes que diferencia o ser humano do resto dos animais. Ele a usa como parte da linguagem, expressando alegria, felicidade ou prazer. A população freqüentemente solicita restaurações compatíveis com os padrões da estética dentária. Este trabalho envolve aspectos relacionados à estética em odontologia restauradora.

Palavras chave: sorriso; odontologia restauradora: material restaurador.

\section{Introducción}

. Desde que el ser humano es capaz de percibir, captar y comprender el orden, simetría y armonía de las cosas, este, propiedades que posee el mundo, estamos en presencia del concepto de belleza. (Martínez Chávez S 2011)

El rostro es una importante área y canal de comunicación no verbal, que juega un rol significativo en las emociones más que ninguna otra parte del cuerpo, el rostro comunica, revela y exhibe 
instantáneamente estados emocionales. Además de ser un área que se utiliza para precisar a un individuo como alguien bello. .(Martínez Chávez B S 2011)

Los orígenes de la estética se remontan a la prehistoria a través del arte y de los instrumentos de uso cotidiano que se conocen actualmente, s e puede ver como ya entonces existía una preocupación por la belleza. Una sonrisa placentera también depende de la calidad y belleza de los elementos dentales y su integración armoniosa. (Martínez Chávez B S 2011)

Aryystas MG. (2010) y Chaple Gil, A M, \& Gispert Abreu, E (2015) hacen referencia que la estética es la ciencia que trata de la belleza y la armonía. Su significado es sumamente subjetivo y relativo, ya que este se encuentra condicionado por diversos factores de orden social, psicológico y cultural, además de estar ligado a la edad y a una época concreta, lo cual determina que varíe según el individuo, grupos poblacionales y el contexto social, va coligada a la proporcionalidad y la armonía, siendo considerado lo desproporcionado como antiestético, así mismo los rasgos faciales desproporcionados y asimétricos son considerados antiestéticos; mientras que los proporcionados, son aceptables, aunque no siempre bellos.

En los momentos actuales existe una creciente petición acerca de los tratamientos médicos para la mejora del aspecto físico, buscando el equilibrio psicológico y la seguridad personal, por necesidad profesional o por exigencia espiritual. La estética es la relación dialéctica de lo bello con lo racional se ha convertido en sinónimo de triunfo en los aspectos más diversos de la vida humana y a todo esto han contribuido los medios audiovisuales que nos orientan a conseguir la perfección de nuestro cuerpo, el culto a la imagen y a la apariencia. (Lorenzo U, A M, Cabo García, R, Gutiérrez Rojas, Á R, Grau León V, \& Otaño Laffite, G (2011).

Al hablar de la odontología, el término estética abarca los aspectos morfológicos armónicos, mientras el de cosmética se relaciona con la técnica, los materiales, el color y la interacción entre ellos. En la práctica se solapan pues es imposible realizar una restauración armónica sin técnica, materiales y color adecuados. (Dell'acqua A, Espinosa Fernandez R, Fernández-Bodereau E, Henao Pérez D, Kohen S, Mondelli J, et al 2006)

La motivación que cada paciente tiene para acudir al tratamiento de odontología es el objetivo central del plan de tratamiento orientado al problema. Este plan de tratamiento no solamente se 
enfoca en problemas, sino también identificando atributos estéticos del paciente, buscando mejorarlos o conservarlos a lo largo del mismo. (Gutiérrez-Rojo J C, * Robles-Villaseñor J F, 2012)

Según Martínez Chávez BS (2011) la estética dental es muy importante porque, como su nombre lo sugiere, abarca todo aquello relacionado con la belleza, la estética o el embellecimiento de sus dientes, en sus muy distintas formas y posibilidades.

Para el ser humano la comunicación y la sonrisa son las puertas de entrada a las relaciones humanas y el cuidado de la boca y la posición dentaria cobra especial importancia. El apiñamiento dentario es uno de los motivos de consulta más frecuente de nuestros pacientes y de ahí cualquier técnica ortodoncia, incluye mecánicas encaminadas a solucionar este problema. ( Di Santi de Modano, J, Vázquez, Victoria B 2016)

El aspecto complejo de la sonrisa depende fundamentalmente de la simetría y proporcionalidad de los dientes, que constituyen dicha sonrisa. Los dientes asimétricos o que no guardan proporción con los dientes circundantes, alteran la sensación de equilibrio y armonía esenciales para una estética ideal. Los labios superiores e inferiores enmarcan el despliegue de los dientes y la encía durante la sonrisa. Las características de los tejidos blandos determinantes en la sonrisa son el grosor de los labios el ancho intercomisural, la apertura interlabial, e índice de la sonrisa (relación entre ancho y altura) y la arquitectura gingival. (Castaño Vega. A 2009)

Existen numerosos problemas que afectan la estética dental como la mal posición de las piezas (espacios entre dientes, inclinaciones...) hasta la variación de la forma de las mismas (dientes afilados, demasiados bajos, etc.), abarcando la coloración dental, sonrisa gingival... entre otros.

\section{Odontología restauradora estética.}

La odontología restauradora se ha convertido en una necesidad para el odontólogo por la gran demanda estética por parte de los pacientes, así como por la implementación de técnicas mínimamente invasivas, siendo imprescindible un correcto diagnóstico y planificación de cada caso, de forma individualizada. (García, A, Momose de Andrade T, Mongruel Gomes O, Gomes, J 2009) 
En la odontología restauradora estética, la percepción de los principios que rigen las formas y los colores están influenciadas por varios factores intrínsecos y extrínsecos importantes como: el conocimiento de las diferentes técnicas y materiales envolviendo sus indicaciones, ventajas, desventajas o limitaciones, y de la propia experiencia y limitaciones del profesional; la relación paciente-profesional, debido a que los pacientes llegan a la consulta con bastante información proveniente de los medios de comunicación y el profesional debe saber orientarlo con relación a sus deseos y expectativas; los aspectos psicológicos y la subjetividad, ya que todo lo relacionado con lo estético tiene una carga emocional muy importante influenciada por la etapa de la historia en que se vive, la cultura, edad y el sexo; y principalmente por la luz, fenómeno sin el cual nuestra percepción y relación con el ambiente que nos rodea sería totalmente diferente a lo que estamos acostumbrados. (García, A, Momose de Andrade T, Mongruel Gomes O, Gomes, J 2009)

Los materiales dedicados a las restauraciones estéticas en odontología han ido evolucionando con rapidez desde finales del siglo pasado y comienzos del actual, dando lugar a la aparición de nuevas técnicas y tratamientos para la rehabilitación estética de los pacientes. (Eades R 2013)

Alvarado Jiménez O (2013) ilustra en su investigación que el comité de Parámetros de Atención del American College of Prosthodontics (ACP), en una publicación realizada en la revista Journal of Prosthodontics el mes de diciembre de 2005 determina algunos de los parámetros, guía a tomarse en cuenta en los tratamientos estéticos, y los enumera de acuerdo a cinco categorías en las cuales el profesional se debe orientar.

\section{Indicaciones de atención:}

Preocupaciones del paciente.

Morfología dentaria inaceptable (desgaste, anomalías congénitas, textura superficial.)

\section{Color}

Diastemas y contactos interproximales.

Mal posición dentaria 
Largo coronario inadecuado debido a erupción pasiva

Restauraciones antiestéticas.

Arquitectura gingival inaceptable

\section{Objetivos Terapéuticos.}

Abordar las preocupaciones del paciente

Mejorar Estética

Respuesta psicosocial positiva

Mejorar la forma dentaria.

Mantener la función

\section{Factores de Riesgo que afectan la calidad del tratamiento.}

Expectativas no realistas del paciente

Falta de comunicación clara

Enfermedad sistémica existente

Enfermedad periodontal

Complicaciones endodónticas

Factores oclusales

Posición y alineamiento dentario

Factores esqueletales

Estructura dentaria inadecuada

Arquitectura periodontal 
Anatomía labial y del carrillo

Complicaciones musculares oro- faciales

Factores psicosociales

Hábitos parafuncionales. (Alvarado Jiménez O 2013)

En esta misma vertiente García, A, et al (2009) reseña que la odontología restauradora cuenta con una serie de parámetros que nos permiten de una forma sistemática y más dinámica un análisis objetivo de la estética. Esos parámetros son los principios estéticos, integrados por componentes horizontales y verticales, actuando como las partes de un rompe-cabezas que, correctamente encastrados y analizados en conjunto, nos permiten alcanzar el éxito del tratamiento restaurador.

\section{Nos referiremos a algunos de los parámetros estéticos en odontología restauradora.}

Forma de la sonrisa: Se debe de tener en cuenta la forma y el tamaño de los labios la cantidad de estructura dentaria y tejido gingival exhibida durante los movimientos. La región labial no solamente indica sexo, edad y raza, sino que también connota personalidad, estados de ánimo y procesos de salud-enfermedad. (Higashi C, Gomes JC, Kina S, Andrade OS, Hirata R 2006)

Los bordes incisales de los dientes antero-superiores junto con el labio inferior, en la mayoría de las veces, describen la forma de un "plato hondo" o "alas de gaviota" debido al menor tamaño de los incisivos laterales. Ambas líneas imaginarias describen curvaturas paralelas generalmente cóncavas hacia coronal y guardan estrecha relación con la presencia y ubicación de los puntos de contacto, los cuales adquieren una posición más hacia apical en sentido de la región posterior. Debe tenerse en cuanta que el paralelismo entre los bordes de los incisivos superiores y la línea interpupilar sirve como planos de orientación para la composición dentofacial. (García, A, Momose de Andrade T, Mongruel Gomes O, Gomes, J 2009)

Otro parámetro que debe ser analizado es la coincidencia y/o paralelismo de las líneas medias maxilar, mandibular, facial e interincisales superior e inferior junto con la simetría que existe a ambos lados de éstas. Este concepto se refiere no solamente al principio de las formas, como también a la posición, color y textura superficial de los elementos dentarios y tejidos blandos. 
Más allá de que la coincidencia de las líneas verticales no se de en el 100\% de las personas, permitiendo así cierto grado de flexibilidad, se torna imprescindible la presencia de equilibrio a ambos lados de estas. (García, A, Momose de Andrade T, Mongruel Gomes O, Gomes, J 2009)

Los bordes incisales de los dientes antero-superiores junto con el labio inferior, en la mayoría de las veces, describen la forma de un "plato hondo" o "alas de gaviota" debido al menor tamaño de los incisivos laterales. Ambas líneas imaginarias describen curvaturas paralelas generalmente cóncavas hacia coronal y guardan estrecha relación con la presencia y ubicación de los puntos de contacto, los cuales adquieren una posición más hacia apical en sentido de la región posterior. Debe tenerse en cuanta que el paralelismo entre los bordes de los incisivos superiores y la línea interpupilar sirve como planos de orientación para la composición dentofacial. (García, A, Momose de Andrade T, Mongruel Gomes O, Gomes, J 2009)

Las alteraciones que pueden provocar desequilibrio de la armonía facial son innumerables, para solucionarlas, la odontología restauradora actualmente cuenta con un abanico de opciones que permiten reestablecer cualquier alteración de color, forma, tamaño, textura superficial y posicionamiento dentario. Desde los procedimientos clásicos de preparaciones para prótesis fijas hasta los menos invasivos como microabrasión y blanqueamiento dental, pasando por las restauraciones directas con resinas compuestas, el odontólogo se puede servir de ellos para cumplir con los requisitos estéticos de los pacientes. Así mismo estos tratamientos deben preservar la función y la salud de los dientes y la encía. (García, A, Momose de Andrade T, Mongruel Gomes O, Gomes, J 2009)

\section{Limpieza Ultrasónica}

Es el procedimiento moderno y sin dolor de eliminación de sarro, placa bacteriana y manchas de nicotina, café, entre otras, mediante vibraciones ultrasónicas o de alta frecuencia. Consigue evitar la enfermedad periodontal y la caries dental que pueden aparecer en el futuro.

\section{Caries dental}

Es la desmineralización de la superficie del diente causada por la placa bacteriana que se adhiere a la superficie dental. La Odontología ultraconservadora se refiere a la eliminación de caries 
dental de forma rápida, segura y conservando la mayor cantidad de tejido dental. Buscando siempre conservar el diente en boca.

\section{Blanqueamiento Dental}

Es un tratamiento dental estético que logra aclarar en varios tonos el color original de las piezas dentales, dejando los dientes más blancos y brillantes. Las técnicas modernas permiten que sea un tratamiento rápido y eficaz.

\section{Prótesis Fijas y Removibles}

Es el tratamiento que rehabilita una o varias piezas dentarias devolviendo su función masticatoria y estética del paciente.

\section{Carillas Dentales}

Es una técnica diseñada para dar una apariencia natural, estética y blanca a la sonrisa. Son pequeñas piezas de porcelana muy delgadas que se fijan en la zona anterior de los dientes consiguiendo embellecer la sonrisa.

\section{Incrustaciones Dentales}

Son restauraciones que se emplean para la reparación de dientes posteriores que han sufrido de caries leves a moderadas, o que tienen alguna fractura importante. Son hechas de materiales altamente estéticos y se requiere de menos desgaste dentario.

\section{Cirugía estética de la encía}

\section{Abarca procedimientos que buscan mejorar el aspecto estético y funcional de la encía.}

Se conoce que el efecto de la odontología restauradora sobre la salud del periodonto está influenciado por las propiedades físicas y químicas de los materiales empleados, el ajuste marginal, la posición del margen coronal, el contorno coronal, el perfil de emergencia, y la oclusión de la restauración. Existen opiniones controvertidas cuando se considera la influencia de los contornos coronales artificiales. Es así como diferentes autores han mencionado que, desde el 
punto de vista periodontal, se prefieren las coronas infracontorneadas. Sin embargo, en pacientes periodontalmente comprometidos, es obligado ubicar márgenes coronales subgingivales y sobrecontornearlos por razones estéticas. Por otra parte, estudios clínicos han presentado el impacto de diferentes perfiles de emergencia sobre la calidad y cantidad de la placa bacteriana. Algunas teorías han tratado de explicar la necesidad de formas particulares de los contornos axiales de coronas parciales y completas, argumentándose que muchas ideas relacionadas con los contornos sugeridos para restauraciones no están basadas en evidencia científica. (Gómez Mira, F., \& Ardila Medina, C.M. (2009), (Schmalz G, Garhammer P 2002), (Carr AB 2003), (Kancyper SG, Koka S 2001),

\section{Aspectos clínicos fundamentales de los contornos coronales.}

Para mantener y estimular funcionalmente la salud de los tejidos gingivales la restauración debe de seguir la anatomía natural del diente. Las lesiones dentales ocasionan con frecuencia cambios en los contornos coronales, como ocurre en los casos de dientes fracturados o desgastados, creando disturbios visuales que influyen sobre la apariencia general de las estructuras bucales. Refieren algunos autores que la retención de placa sobre las superficies bucales y linguales se presenta en primer lugar debajo de la protuberancia dental supragingival, se plantea que el sobrecontorno de las restauraciones protésicas es uno de los factores iatrogénicos que conducen a la acumulación de placa bacteriana sobre las coronas, ocasionando inflamación y sangrado de los tejidos periodontales, especialmente en las superficies proximales. .(Gómez Mira, F., \& Ardila Medina, C.M.. (2009),

Según Goodacre et al indican que la salud periodontal puede mantenerse en presencia de márgenes intracreviculares, lo cual requiere restauraciones adecuadamente contorneadas con márgenes satisfactorios y tratamiento cuidadoso de los tejidos duros y blandos asociados con la preparación dentaria.

\section{Resultados de restauraciones estéticas}

Contenido de estudio realizado por Hernández Núñez et al (2015), la utilización de resinas compuestas como alternativa ante la hipomineralización se restableció la estética, la función y el equilibrio perdidos, en un tiempo razonable; además se lograron expectativas satisfactorias a 
largo plazo y no solo como una solución provisional para dientes anteriores con pigmentación u otras alteraciones del tejido dentario.

Refiere Chaple Gil et al (2015), que las técnicas para tratar las afecciones estéticas son muy variadas y específicamente en el campo de las resinas compuestas fotopolimerizables, los avances tecnológicos se suceden con gran rapidez generando diversos productos, por lo que resulta útil seguir, entre otras, las recomendaciones de realizar limpieza de la superficie de trabajo, seleccionar el color y tipo de resina indicados en cada caso, realizar preparaciones cavita rías mínimas con biseles, si es necesario, emplear técnicas de incremento en la realización de las restauraciones, polimerizar evitando grandes reacciones de contracción y pulir adecuadamente las restauraciones. .

En la contemporaneidad consta un desasosiego en su generalidad por la estética dental debido a su función social, expresión del rostro, comunicación interpersonal y aceptación. Por ello la práctica odontológica debe renovarse continuamente para satisfacer las demandas de la población sin descuidar el aspecto funcional.

\section{Referencias Bibliográficas}

Aryystas MG. Facial esthetics: Where dentristry meets artistry. (2012) Journal: Compendium of continuing education in dentistry. Jamesburg, N.J. 31(4):258-9

Alvarado Jiméne O. (2013). Parámetros Estéticos en Prótesis Fija: Revisión Descriptiva. Recuperado de.

http://dspace.ucuenca.edu.ec/bitstream/123456789/23480/3/Par\%C3\%A1metros\%20Est\%C3\%A 9ticos\%20en\%20Pr\%C3\%B3tesis\%20Fija\%2C\%20Revisi\%C3\%B3n\%20Descriptiva.pdf

Castaño Vega. A. (2009). Análisis de la sonrisa en pacientes con tratamiento ortodoncico fianlizado. Recuperado de. repositorio.usfq.edu.ec/bitstream/23000/539/1/90346.pdf

Carr AB. (2003) Effect of prosthetic remedial treatments on the oral health status of individuals and populations. Int J Prosthodont ;16 Suppl: 55-8.

Chaple Gil, Alain Manuel, \& Gispert Abreu, Estela de los Ángeles. (2015). Recomendaciones para el empleo práctico de resinas compuestas en restauraciones estéticas. Revista Cubana de 
Estomatología, 52(3), 293-313. Recuperado de

http://scielo.sld.cu/scielo.php?script=sci_arttext\&pid=S0034-

$75072015000300007 \& \operatorname{lng}=$ es\&tlng=es

Dell'acqua A, Espinosa Fernandez R, Fernández-Bodereau E, Henao Pérez D, Kohen S, Mondelli J, et al. (2006). Estética en Odontología Restauradora. 1a ed. Madrid: Editorial Ripano S.A.; 2006.

Di Santi de Modano, J, Vázquez, V B. (2016). Maloclusión Clase I: Definición, clasificación, características clínicas y tratamiento. Revista latinoamericana y odontopediatria. ISSN1317-5823

Eades R. (. 2013)Conservative treatment of tooth wear to improve function and aesthetics. Prim Dent ;2(4). Recuperado de http://openurl.ingenta.com/content/nlm?genre=article\&issn=2050$1684 \&$ volume $=2 \&$ issue $=4 \&$ spage $=56 \&$ aulast $=$ Eades

García, A, Momose de Andrade T, Mongruel Gomes O, Gomes, J , (2009) Aplicación clínica de los parámetros estéticos en odontología restauradora. Recuperado de https://www.actaodontologica.com/ediciones/2009/1/art-4/

Gutiérrez-Rojo J C, * Robles-Villaseñor J F. (2012). La estética en odontología. Revista Tame; $1(1): 24-28$.

Gómez Mira, F., \& Ardila Medina, C.M.. (2009). Contornos y perfil de emergencia: aplicación clínica e importancia en la terapia restauradora. Avances en Odontoestomatología, 25(6), 331338. Recuperado de http://scielo.isciii.es/scielo.php?script=sci_arttext\&pid=S021312852009000600005\&lng=es\&tlng=es.

Goodacre CJ, Campagni WV, Aquilino SA. (2001) Tooth preparations for complete crowns: an art form based on scientific principles. J Prosthet Dent.;85:363-76

Hernández Núñez, Yuritza; Ramos Rodríguez, Dileidy; Enriquez León, Anamary (2015). Carillas estéticas con la utilización de resinas compuestas como alternativa ante la hipomineralización. Presentación de un caso

MediSur, 13(3), pp. 429-435 
Higashi C, Gomes JC, Kina S, Andrade OS, Hirata R. (2006) Planejamento Estético em Dentes Anteriores. In: Miyashita E. Odontologia Estética: Planejamento e técnica. $1^{\text {a }}$ ed. São Paulo: Editora Artes Médicas Brasil, . p. 139-54.

Kancyper SG, Koka S. (2001) The influence of intracrevicular crown margins on gingival health: preliminary findings. J Prosthet Dent ;85: 461-5.

Lorenzo Uribazo, Adriana M, Cabo Garcia, Rogelio, Gutiérrez Rojas, Ángela R, Ileana, Grau LeónV, \& Otaño Laffite, Gladis. (2011). Comportamiento de proporciones divinas en mediciones dentales de individuos con normoclusión y maloclusión. Revista Habanera de Ciencias Médicas, 10(3) Recuperado de 2018, http://scielo.sld.cu/scielo.php?script=sci_arttext\&pid=S1729519X2011000300014\&lng=es\&tlng=es

Martínez ChavezB S. (2011). Manual de ortodoncia 1. Universidad Autonoma Benito Juarez de Oaxaca. México. Ortodoncia Recuperado de. http://foposgrado.org/wpcontent/uploads/2014/01/ortodoncia.pdf

Schmalz G, Garhammer P. (2002) Biological interactions of dental cast alloys with oral tissues. Dent Mater 2002; 18:396-406. 